\title{
Computational analyses for cancer biology based on exhaustive experimental backgrounds
}

\author{
Jun Koseki', Masamitsu Konno², Hideshi Ishii' \\ 'Department of Medical Data Science, Osaka University, Osaka, 565-0871, Japan. \\ ${ }^{2}$ Department of Frontier Science for Cancer and Chemotherapy, Osaka University, Osaka, 565-0871, Japan.
}

Correspondence to: Prof. Hideshi Ishii, Department of Medical Data Science, Osaka University, Osaka, 565-0871, Japan.

E-mail: hishii@gesurg.med.osaka-u.ac.jp

How to cite this article: Koseki J, Konno M, Ishii H. Computational analyses for cancer biology based on exhaustive experimental backgrounds. Cancer Drug Resistance 2019;2:419-27. http://dx.doi.org/10.20517/cdr.2019.33

Received: 23 Apr 2019 First Decision: 5 Jul 2019 Revised: 18 Jul 2019 Accepted: 26 Jul 2019 Published: 19 Sep 2019

Science Editor: Helen M. Coley Copy Editor: Jia-Jia Meng Production Editor: Jing Yu

\begin{abstract}
Antitumor drug therapy plays a very important role in cancer treatment. However, resistance to chemotherapy is a serious issue. Many studies have been conducted to understand and verify the cause of chemoresistance from multiple points of view such as oncogenes, tumor suppressor genes, DNA mutations and repairs, autophagy, cancer stemness, and mitochondrial metabolism and alteration. Nowadays, not only medical data from hospitals but also public big data exist on internet websites. Consequently, the importance of computational science has vastly increased in biological and medical sciences. Using statistical or mathematical analyses of these medical data with conventional experiments, many researchers have recently shown that there is a strong relationship between the biological metabolism and chemoresistance for cancer therapy. For example, folate metabolism that mediates onecarbon metabolism and polyamine metabolism have garnered attention regarding their association with cancer. It has been suggested that these metabolisms may be involved in causing resistance to chemotherapy.
\end{abstract}

Keywords: In silico drug design, trans-omics analysis, computational analyses, cancer biology

\section{INTRODUCTION}

Incidence of cancer is increasing worldwide, and there are some challenges in cancer treatment, including resistance to antitumor drugs. The drug resistance in cancer treatment can be of two types: acquired and congenital. Cancer therapy is typically very effective at the start of the treatment, with tumor

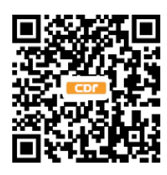


degeneration being observed; however, recurrence and metastasis of cancer are often observed thereafter. With chemotherapy, cancer progression is a grave problem. Therefore, several studies have investigated the causes of chemotherapy resistance from multiple points of view such as oncogenes, tumor suppressor genes, DNA mutations and repairs, autophagy, cancer stemness, and mitochondrial metabolism and alteration $^{[1-7]}$. Although each one of these individually is not a cause of drug resistance, but the complex relationship among them may result in chemoresistance. Because of this relationship, it has been recently determined that differences in the biological metabolism pathways regarding the presence or absence of the characteristic of chemoresistance are related to drug resistance in cancer therapy. In this review, we aim to summarize the research on antitumor drug resistance and cancer cell characteristics.

\section{ONCOGENES AND TUMOR SUPPRESSOR GENES}

Cancer tissue is considered to be a population of abnormal cells that arise from normal cells. Normal cells proliferate depending on the surrounding conditions, whereas cancer cells continue to uncontrollably proliferate. Cancer occurs as a result of errors in the genes of normal cells over many years ${ }^{[8-12]}$. There are two types of gene errors: mutations and epigenetic changes. These errors occur in cases where gene activation causes cell proliferation and acts as an accelerator (activation of oncogenes) and in cases where a braking action for arresting cell growth is not activated (inactivation of tumor suppressor genes). Therefore, many studies have reported on oncogenes and tumor suppressor genes.

Typical examples of oncogenes include $c-M Y C^{[13-15]}$ and $R A S^{[16-18]} . M Y C$ family of genes is known to cause cancer by an overexpression of the product protein, $\mathrm{c}-\mathrm{MYC}$, for some reason combined with a loss of the original function of cell cycle control. Translocation of the $c-M Y C$ gene close to a transcriptionally active immunoglobulin gene results in overexpression. This behavior has been observed in human Burkitt's lymphoma, diffuse large B-cell lymphoma, and some carcinomas. However, in some cancers such as colon cancer, there is an exception where the survival rate may be better if the expression is $\operatorname{high}^{[19,20]}$. The $R A S$ family of genes produces a RAS protein that has an important role in transmitting signals that promote cell proliferation. There are three types of RAS gene: KRAS, NRAS, and HRAS. It is well known that the epidermal growth factor receptor (EGFR) on the cell surface is involved in one of the mechanisms involved in the proliferation of cancer cells. Normally, the RAS gene controls cell growth. However, in case of a RAS gene with a significant mutation, cell proliferation signals continue to be emitted, even if EGF and EGFR are not bound. As a result, cancer cell proliferation is activated.

Many studies have reported on tumor suppressor genes. The $P_{53}$ gene $\mathrm{e}^{[21-24]}$ and retinoblastoma1 $(R B 1)$ gene susceptibility ${ }^{[25,26]}$ are the representative examples. They are known to play important roles in cell death induction, cell proliferation suppression, and DNA repair. P53 is a stress-induced transcription factor that can promote cell cycle arrest, apoptosis, and senescence. In addition, it is involved in the regulation of metabolic pathways and cytokines required for embryo transfer. Because P53 plays these important roles, it would be natural that any mutation in the P53 gene will promotes P53 protein dysfunction and cancer development. Furthermore, $R B 1$ is a known tumor suppressor gene, which is characterized as a "gatekeeper." Mutations in the $R B 1$ gene occur in almost all familial and sporadic forms of RB1. The RB1 gene produces the RB1 protein, which plays a role in the repression of the E2F transcription factor family. For tumor initiation, this inactivation is a rate-limiting step. Thus, the relationship between various genes (oncogenes and tumor suppressor genes) and cancer has been reported, and it is a well-established fact that cancer results from genetic errors. Any change in the function of the above genes induces epigenetic changes and biological metabolisms in cancer cells.

\section{METABOLISM IN NORMAL CELLS AND CANCER CELLS}

There are significant differences in metabolism between normal cells and cancer cells ${ }^{[27]}$. The Warburg effect is representative of the metabolism in cancer cells; however, our understanding of the effect in terms 
of cancer biology remains incomplete, as is true for other metabolic changes that characterize cancer tissue $^{[28-31]}$. In normal cells, glucose is metabolized to carbon dioxide in the presence of oxygen, although it produces large amounts of lactic acid only in hypoxic conditions. However, in cancer cells, a large amount of lactic acid is produced regardless of the amount of oxygen. Glycolysis in cancer cells is closely related to the rate of adenosine $5^{\prime}$-triphosphate (ATP) consumption ${ }^{[32]}$. Cancer cells need to balance the catabolism that produces ATP with the need for metabolism that promotes biosynthesis and cell division throughout the cell. The aerobic glycolytic system can reportedly balance many of the metabolic requirements for the growth of cancer cells. We have mentioned above that a large amount of lactic acid is produced in cancer cells, and it has become clear that lactic acid is used as a nutrient in some cancer cells ${ }^{[33]}$.

In many cancer cells, metabolic pathways are maintained by oxidative phosphate using multiple nutrients. Glucose is not the only substrate used for oxidative phosphorylation in cancer cells ${ }^{[34,35]}$. A pathway that metabolizes glutamine to $\alpha$-ketoglutarate has been reported ${ }^{[36]}$. Glutamine is required for cell growth in many cancer cells, and it is more abundantly metabolized than other non-essential amino acids ${ }^{[37,38]}$. Glutamine metabolism is a known source for the synthesis of macromolecules such as nucleotides, proteins, and lipids. However, it also supports nicotinamide adenine dinucleotide phosphate production and anaplasia in the proliferation of cancer cells. Thus, some amino acids and ions are also important factors associated with survival and maintenance of cancer cells.

In addition, the relationship between oxidative damage and cancer malignancy has also been reported for a long time ${ }^{[39,40]}$. Reactive oxygen species (ROS), such as hydrogen peroxide, superoxide, hydroxyl radical, and singlet oxygen, is well known. It has an important role in immune function and defense against infection. It is also used as a physiologically active substance for signal transduction, cell differentiation, and apoptosis. However, high level of ROS is very toxic to cells. It is reported that the expression level of antioxidant enzymes in cancer is changed both in vivo and in vitro experiments ${ }^{[30]}$. Generally, oxidative stress and redox signaling are involved in the development of cancer and ROS could influence the phenotypic behavior of cancer cells and their responsiveness to therapeutic interventions ${ }^{[40]}$. On the other hand, it has also been reported that the enhancement of oxidative stress in normal cells limits tumor development and tumor progression. And then, if the oxidative stress is not controlled, the level of ROS turns higher to the point of causing senescence or apoptosis and turns into a tumor suppressor ${ }^{[41]}$. Then, the fact means that strategic targeting of antioxidant system could be effective for undermining new tumor cells ${ }^{[42]}$.

Further, it was reported that Raf/MEK/ERK pathway had an important role to drug resistance ${ }^{[43]}$. This pathway is a signal transduction system responsible for cell growth, and the abnormal activation of this pathway is known that normal cells turn into cancer cells. In some type of cancer, this pathway regulates the expression level of drug pumps and anti-apoptotic molecules. McCubrey et al ${ }^{[43]}$ show that ectopic expression of Raf induces increased expression of Mdr-1 and Bcl-2 associated with drug resistance.

Recently, the significance of the mitochondrial metabolism is also garnering attention. In some cancers, mutations have been observed in mitochondrial enzyme genes; however, the mitochondrial function is not lost in many cancer cells ${ }^{[4]}$. Folate metabolism in mitochondria is known to mediate one-carbon metabolism ${ }^{[45-52]}$ [Figure $\left.1 \mathrm{~A}\right]$. It is closely related to cancer cell characteristics ${ }^{[53,54]}$. Serine hydroxymethyltransferase 2, methylenetetrahydrofolate dehydrogenase 2 (MTHFD2), and aldehyde dehydrogenase 1 family member L2 are known as the genes that control the metabolic cycle of tetrahydrofolate in mitochondria. In fact, among patients with colorectal cancer and lung adenocarcinoma, those with high expression of these genes have a shorter overall survival rate than those with low $\operatorname{expression}^{[53]}$.

As mentioned above, the cancellation of normal cells greatly alters the biological metabolism of cancer cells compared with that of normal cells. It is caused by genomic or epigenetic errors that are important 
A

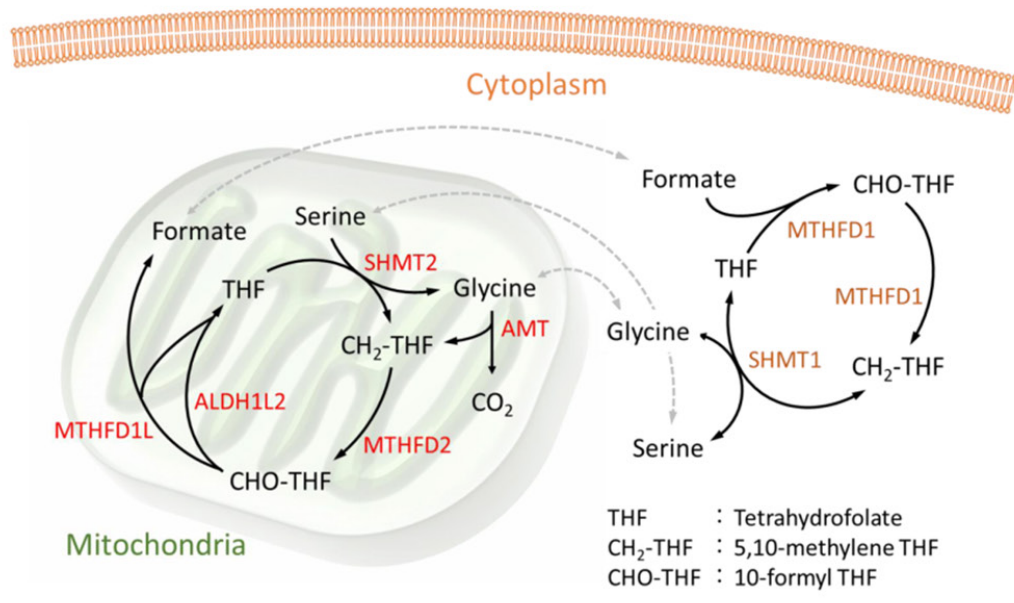

B

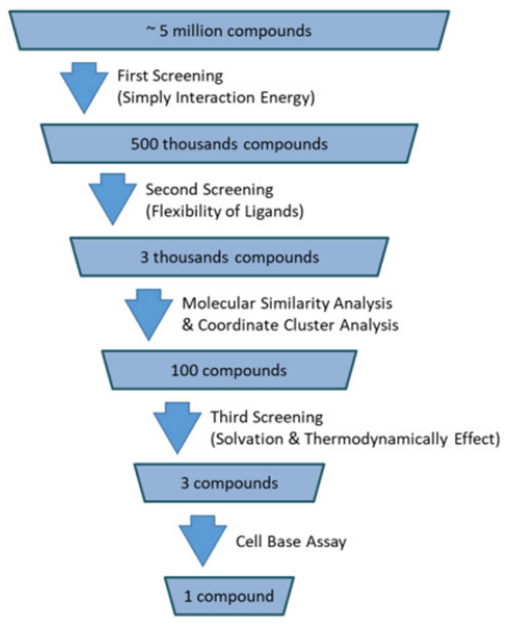

Figure 1. A: Schematic diagram of the metabolic cycle of THF and the one-carbon (1C) metabolic pathway in folate metabolism, which are regulated by SHMT2, AMT, MTHFD2, ALDH1L2, and MTHFD1L in mitochondria and that of MTHFD1 and SHMT1 in cytoplasm; B: Candidate compound search procedure with in silico molecular docking and a cell-based assay. THF: tetrahydrofolate; SHMT2: serine hydroxymethyltransferase 2; AMT: aminomethyltransferase; MTHFD2: methylenetetrahydrofolate dehydrogenase 2; ALDH1L2: aldehyde dehydrogenase 1 family member L2; MTHFD1L: methylenetetrahydrofolate dehydrogenase 1 like; MTHFD1: methylenetetrahydrofolate dehydrogenase 1

for carcinogenesis. Generally, many cancer driver genes enhance nutrient intake. This means that the transformation of cancer cells is strongly related to increased glucose uptake ${ }^{[5,56]}$. In human cancers, activation of the phosphatidylinositol-3 kinase (PI3K) signaling pathway is frequently observed. Reportedly, $\mathrm{PI} 3 \mathrm{~K}$ is involved in glucose metabolism through the insulin signal leading to glucose uptake ${ }^{[57]}$. Conversely, just as some gene mutations lead to oncogenesis, metabolic errors in some cells may also be a direct cause of oncogenesis. These facts indicate the possibility of treating cancer by controlling certain metabolisms. Therefore, drug discovery research has also been performed regarding antitumor drugs targeting certain metabolisms ${ }^{[54]}$. Our group has performed in silico molecular docking to search for effective candidate compounds [Figure 1B]. Consequently, very promising compounds potentially targeting MTHFD2 could be found earlier. Our statistical analyses using clinical data led us to predict that compared with the conventional target dihydrofolate reductase, MTHFD2 is a more efficient drug target for cancer therapy with less side effects in normal cells ${ }^{[53]}$.

So far, we have focused on the differences between normal cells and cancer cells. However, cancer tissue is not a group of cancer cells that have homogeneous properties but a collection of heterogeneous cancer cells that exhibit different biological characteristics. A cancer stem cell model has been proposed to explain this heterogeneity ${ }^{[8,9]}$.

\section{CANCER STEM CELL MODEL}

Reportedly, tumor cells exhibit heterogeneity in their proliferative ability. The fact that only some cells have the ability to form tumors was mentioned for the first time in a paper on lymphoma in mice ${ }^{[58]}$. Transplantation of human hematopoietic stem cells into NOD/SCID mice has shown to repopulate human hematopoietic cell lines over time ${ }^{[59]}$, and when similar transplantation is performed using hematopoietic stem cells of patients with leukemia, mice develop leukemia ${ }^{[60]}$. These behaviors indicate that leukemia develops when hematopoietic stem cells become tumor-initiating cells. The tumor-initiating cells are defined as cancer stem cells (CSCs) that have three stem-cell-like characteristics: differentiation, selfrenewal, and proliferation maintenance. CSCs have been defined in many solid tumors such as breast 
cancer $^{[61]}$, glioblastoma ${ }^{[62]}$, head and neck cancer ${ }^{[63]}$, some digestive organ cancers ${ }^{[64,65]}$, and other types of cancer. CSCs have the property of therapy resistance ${ }^{[3,7]}$. Thus, many biomarkers have been reported to define and distinguish these CSCs ${ }^{[6,67]}$. Recently, it has been reported that CSCs in breast cancer and gliomas may be identified using fluorescent protein with a degron motif, which is broken down by proteasomes. Because the proteasome activity in CSCs is lower than that in non-CSCs, CSCs yield fluorescence and non-CSCs do not ${ }^{[68]}$. Furthermore, it has been verified in other types of cancers that the cells identified using the abovementioned techniques retain cancer stem-cell-like properties and maintain chemoradiation resistance ${ }^{[69,70]}$.

Epithelial-mesenchymal transition (EMT) is a change because of which epithelial cells lose their characteristics obtained at differentiation and acquire mesenchymal traits. It has been reported that EMT contributes to tumor progression by enhancing the infiltrative metastatic potential of cancer cells ${ }^{[71,72]}$ and by increasing the resistance to antitumor drugs ${ }^{[73]}$.

CSCs have very different biological characteristics from non-CSCs constructing majority of the tumor tissue. CSCs exhibit characteristics such as very slow cell cycle and drug resistance. Therefore, for complete cure of cancer, it is necessary to completely kill CSCs. Some recent studies have shown the possibility that epigenetic regulation can control cancer stemness ${ }^{[74,75]}$. Histone demethylating enzyme plays a role in the regulation of cell proliferation and maintenance of stemness. Therefore, a reduced activity of this enzyme leads to cancer cell death. A study has focused on targeting histone demethylase using small molecules ${ }^{[76]}$; however, there are many challenges to cancer therapy targeting CSCs.

A little aside from this, it is essential for cancer cell growth to have unlimited replication capacity. On the other hand, in normal cells, the number of cell divisions is limited. It is known that the unlimited proliferation ability of cancer cells is involved in telomeres protecting the ends of chromosomes ${ }^{[77-80]}$. In normal cells, their length decreases as cell division repeats, and eventually their ability to protect the ends of chromosomes is lost. Telomerase is a DNA polymerase that adds a telomeric repeat to the end of telomeric DNA. Telomerase is almost absent in normal cells but is expressed at significant levels in most cancer cells as is the case with normally stem cells. Telomere activity is associated with resistance to both replicative senescence and induction of crisis apoptosis. On the other hand, it is reported that suppression of telomere activity leads to activation of either replicative senescence or crisis apoptosis.

\section{COMPUTATIONAL ANALYSES}

Advances in observational techniques for experimental equipment have also increased the volume of the available data. Consequently, omics analyses such as those of methylome, transcriptome, proteome, and metabolome have enabled more comprehensive understanding of the biological molecules for exhaustive research. As the performance of computing devices has improved, rapid advances have made it possible to collectively calculate large volumes of data. With advances in the computer technology, innovative analytical methods have been developed to evaluate the correlations between multiple experimental data. These new analytical methods also make it possible to gain new knowledge that could not be achieved with conventional methods. To date, many studies using computational science have been conducted in the field of cancer research ${ }^{[81,82]}$.

As mentioned above, the amount of biological data in the medical research field is large. Therefore, conventional statistical methods have been used as a very powerful tool. Recently, trans-omics methods were proposed, which is for mechanically reconstructing a large-scale network across multiple omics layers with integration multi-omics data from samples prepared under the same conditions ${ }^{[83,84]}$. However, it was said that some technical and analytical improvements will still be required to make this approach a 

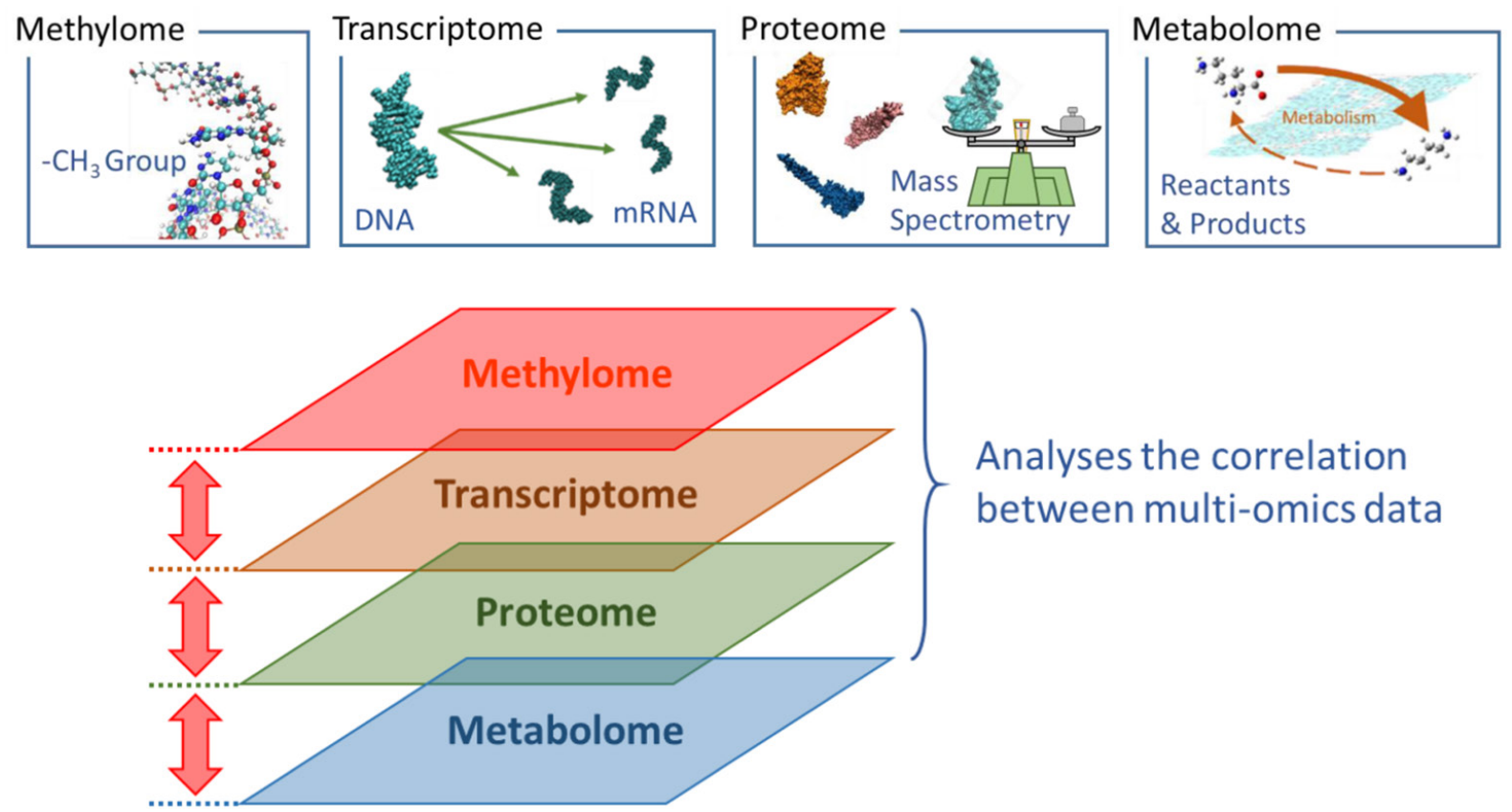

Analyses the correlation between multi-omics data

Figure 2. Schematic diagram of trans-omics analysis. There is a correlation between each omics data (layer), and some changes should affect the data of the separate upper and lower layers. New findings are derived by a comprehensive analysis of each layer and a correlation analysis between the layers

reliable approach ${ }^{[83]}$. On the other hand, one of the trans-omics method developed by by Kosekiet al. ${ }^{[85]}$ and Konno et al ${ }^{[86]}$ has been groundbreaking in identifying some biological metabolisms that may be involved in anticancer drug resistance in cancer cells. Trans-omics analyses are a method of grasping the global network of biological molecules by hierarchically linking multiple omics data using statistics or mathematical techniques [Figure 2]. The experimental results obtained using a conventional single omics analysis are just a snapshot at one time. However, the trans-omics method, using some multi-omics data, has made it possible to predict (interpolation/extrapolation) changes over time through correlation analyses among the data. Koseki et al. ${ }^{[85]}$ have created a novel trans-omics method to predict the changes in a specific reaction rate and performed prediction analyses using transcriptome and metabolome data to compare CSCs and nonCSCs. Furthermore, they have suggested that the polyamine metabolic pathway plays an important role in antitumor drug resistance in CSCs. The polyamine metabolism involves the reaction from ornithine to spermine via putrescine and spermidine. In non-CSCs, the inflow to putrescine stands out after exposure to an antitumor agent, and its reaction rate slows over time. Conversely, it appears that the polyamine reaction in CSCs is controlled in a manner that increases ornithine to a certain level. Furthermore, highlevel polyamines inhibit lysine demethylase 1A (LSD1) enzyme activity because polyamine oxidase (a polyamine catabolic enzyme) is highly similar in overall structure to $\operatorname{LSD} 1^{[87]}$. Thus, it has been proposed that it could result in the death of cancer cells. This means that CSCs regulate polyamine metabolism to protect their own survival from antitumor agents. Application of computational analyses in this manner has made it possible to identify biological reactions that contribute to antitumor drug resistance.

\section{CONCLUSION}

Earlier, most computational analyses were used in physical and chemical sciences rather than in life and medical sciences. However, they are now widely used in many scientific areas. The computational approach is not only complementary to the results of conventional experimental research but it can also significantly improve the speed and accuracy of analysis. Furthermore, using computational analyses makes it possible for one to achieve new results and interpretations that may not be understood using only conventional 
experimental systems. Through computational analyses of differences in cancer cell characteristics observed in some experiments such as those on methylomes, transcriptomes, and metabolomes, it has become possible for researchers to extract the biological metabolism that influences cancer cell characteristics such as antitumor drug resistance. Therefore, computational analyses such as statistical and trans-omics analyses may become very powerful tools in answering some scientific interrogations in the life and medical sciences.

\section{DECLARATIONS}

\section{Authors' contributions}

Collected some information for this review: Koseki J, Konno M

Wrote the manuscript: Koseki J, Konno M

Performed the final check and data management: Ishii $\mathrm{H}$

\section{Availability of data and materials}

Not applicable.

\section{Financial support and sponsorship}

Our research group was funded by Taiho Pharmaceutical Co., Ltd. (Tokyo, Japan), UNITECH Co., Ltd. (Chiba, Japan), IDEA Consultants Inc. (Tokyo, Japan), Kinshu-kai Medical Corporation (Osaka, Japan).

\section{Conflicts of interest}

All authors declared that there are no conflicts of interest.

\section{Ethical approval and consent to participate}

Not applicable.

\section{Consent for publication}

Not applicable.

\section{Copyright}

(c) The Author(s) 2019.

\section{REFERENCE}

1. Bush JA, Li G. Cancer chemoresistance: The relationship between P53 and multidrug Transporters. Int J Cancer 2002;98,323-30.

2. Wang W, Kryczek I, Dostál L, Lin H, Tan L, et al. Effector T Cells Abrogate Stroma-Mediated Chemoresistance in Ovarian Cancer. Cell 2016;165:1092-105.

3. Prieto-Vila M, Takahashi R, Usuba W, Kohama I, Ochiya T, et al. Drug Resistance Driven by Cancer Stem Cells and Their Niche. Int J Mol Sci 2017;18:pii:E2574.

4. Brasseur K, Gévry N, Asselin E. Chemoresistance and targeted therapies in ovarian and endometrial cancers. Oncotarget 2017;8:400842.

5. Zheng HC. The molecular mechanisms of chemoresistance in cancers. Oncotarget 2017;8:59950-64.

6. Jo Y, Choi N, Kim K, Koo HJ, Choi J, et al. Chemoresistance of Cancer Cells: Requirements of Tumor Microenvironment-mimicking In Vitro Models in Anti-Cancer Drug Development. Theranostics 2018;8:5259-75.

7. Phi LTH, Sari IN, Yang YG, Lee SH, Jun NL, et al. Cancer Stem Cells (CSCs) in Drug Resistance and their Therapeutic Implications in Cancer Treatment. Stem Cells Int 2018;2018:5416923.

8. Dick JE. Stem cell concepts renew cancer research. Blood 2008;112:4793-807.

9. Wang JC. Good cells gone bad: the cellular origins of cancer. Trend Mol Med 2010;16:145-51.

10. Tomasetti C, Voelstein B, Parmigiani G. Half or more of the somatic mutations in cancers of self-renewing tissues originate prior to tumor initiation. Proc Natl Acad Sci U S A 2013;110:1999-2004.

11. Tomasetti C, Vogelstein B. Variation in cancer risk among tissues can be explained by the number of stem cell divisions. Science 2015;347:78-81. 
12. Tomasetti C, Li L, Vogelstein B. Stem cell divisions, somatic mutations, cancer etiology, and cancer prevention. Science 2017;355:1330-4.

13. Nilsson JA, Cleveland JL. Myc pathways provoking cell suicide and cancer. Oncogene 2003;22:9007-21.

14. Miller DM, Thomas SD, Islam A, Muench D, Sedoris K. c-Myc and Cancer Metabolism. Clin Cancer Res 2012;18:5546-53.

15. Chen H, Liu H, Qing G. Targeting oncogenic Myc as a strategy for cancer treatment. Signal Transduct Target Ther 2018;3:5.

16. Campbell PM, Der CJ. Oncogenic Ras and its role in tumor cell invasion and metastasis. Semin Cancer Biol 2004;14:105-14.

17. Pylayeva-Gupta Y, Grabocka E, Bar-Sagi D. RAS oncogenes: weaving a tumorigenic web. Nat Rev Cancer 2011;11:761-74.

18. Fernández-Medarde A, Santos E. Ras in Cancer and Developmental Diseases. Genes Cancer 2011;2:344-58.

19. Toon CW, Chou A, Clarkson A, DeSilva K, Houang MC. Immunohistochemistry for Myc Predicts Survival in Colorectal Cancer. PLoS ONE 2014;9:e87456.

20. Koseki J, Colvin H, Fukusumi T, Nishida N, Konno M, et al. Mathematical analysis predicts imbalanced IDH1/2 expression associates with 2-HG-inactivating $\beta$-oxygenation pathway in colorectal cancer. Int J Oncol 2015;46:1181-91.

21. Rivlin N, Brosh R, Oren M, Rotter VN. Mutations in the p53 Tumor Suppressor Gene: Important Milestones at the Various Steps of Tumorigenesis. Genes Cancer 2011;2:466-74.

22. Levine AJ, Oren M. The first 30 years of p53: growing ever more complex. Nat Rev Cancer 2009;9:749-58.

23. Lane D, Levine A. p53 Research: The Past Thirty Years and the Next Thirty Years. Cold Spring Harb. Perspect. Biol 2010;2:a000893.

24. Garritano S Inga A, Gemignani F, Landi S. More targets, more pathways and more clues for mutant p53. Oncogenesis 2013;2:e54.

25. Macleod KF. The RB tumor suppressor: a gatekeeper to hormone independence in prostate cancer? J Clin Invest 2010;120:4179-82.

26. Oser MG, Fonseca R, Chakraborty AA, Brough R, Spektor AM, et al. Cells Lacking the RB1 Tumor Suppressor Gene Are Hyperdependent on Aurora B Kinase for Survival. Cancer Discov 2019;9:230-47.

27. Vander Heiden MG, Cantley LC, Thompson CB. Thompson, Understanding the Warburg Effect: The Metabolic Requirements of Cell Proliferation. Science 2009;324:1029-33.

28. Warburg O. On the Origin of Cancer Cells. Science 1956;123:309-14.

29. Gatenby RA, Gillies RG. Why do cancers have high aerobic glycolysis? Nat Rev Cancer 2004;4:891-9.

30. DeBerardinis RJ, Lum JJ, Hatzivassiliou G, Thompson CB. The Biology of Cancer: Metabolic Reprogramming Fuels Cell Growth and Proliferation. Cell Metab 2008;7:11-20.

31. Hsu PP, Sabatini DM. Cancer Cell Metabolism: Warburg and Beyond. Cell 2008;134:703-7.

32. Racker E. Why do tumor cells have a high aerobic glycolysis? J Cell Physiol 1976;89:697-700.

33. Sonveaux P, Végran F, Schroeder T, Wergin MC, Verrax J, et al. Targeting lactate-fueled respiration selectively kills hypoxic tumor cells in mice. J Clin Invest 2008;118:3930-42.

34. Guppy M, Leedman P, Zu X, Russell V. Contribution by different fuels and metabolic pathways to the total ATP turnover of proliferating MCF-7 breast cancer cells. Biochem J 2002;364:309-15.

35. DeBerardins RJ, Mancuso A, Daikhin E. Beyond aerobic glycolysis: Transformed cells can engage in glutamine metabolism that exceeds the requirement for protein and nucleotide synthesis. Proc Natl Acad Sci U S A 2007;104:19345-50.

36. Miyo M, Konno M, Nishida N, Sueda T, Noguchi KM. Miyo, et al. Metabolic Adaptation to Nutritional Stress in Human Colorectal Cancer. Sci Rep 2016;6:38415.

37. Reitzer LJ, Wice BM, Kennell D. Evidence That Glutamine, Not Sugar, Is the Major Energy Source for Cultured HeLa Cells. J Biol Chem 1979;254:2669-76.

38. Wise DR, DeBerardinis RJ, Mancuso A. Myc regulates a transcriptional program that stimulates mitochondrial glutaminolysis and leads to glutamine addiction. Proc Natl Acad Sci U S A 2008;105:18782-7.

39. Oberley TD. Oxidative Damage and Cancer. Am J Pathology 2002;160:403.

40. Sabharwal SS, Schumacker PT. Mitochondrial ROS in cancer: Initiatiors, amplifiers or an Achilles' hell? Nat Rev Cancer 2014;14:709-21.

41. Harris IS, Treloar AE, Inoue S, Sasaki M, Gorrini CI, et al. Glutathione and Thioredoxin Antioxidant Pathways Synergize to Drive Cancer Initiation and Progression. Cancer Cell 2015;27:211-22.

42. Schumacker PT. Reactive Oxygen Species in Cancer: A Dance with the Devil Cancer. Cancer Cell 2015;27:156-7.

43. McCubrey JA, Steelman LS, Chappell WH, Abrams SL, Wong EW, et al. Roles of the Raf/MEK/ERK pathway in cell growth, malignant transformation and drug resistance. Biochim Biophys Acta 2007;1773:1263-84.

44. Weinhouse S. The Warburg hypothesis fifty years lataer. Z Krebsforsch 1976;87:115-26.

45. M. J. Coon, W. G. Robinson, Amino acid metabolism. Annu Rev Biochem 1958;27:561-612.

46. Jaenicke L. Vitamin and coenzyme function: Vitamin B12 and Folic Acid. Annu Rev Biochem 1964;326:287-316.

47. Brown GM. Biogenesis and Metabolism of Folic Acid (Ch 24). In: Greenberg DM, editor. Metabolic Pathways. New York: Vol IV Academic Press; 1970. pp:383-410.

48. Jabrin S, Ravanel S, Gambonnet B. One-carbon metabolism in plants. Regulation of tetrahydrofolate synthesis during germination and seedling development. Plant Physiol 2003;131:1431-9.

49. Duthie SJ, Narayanan S, Sharp L, Little J, Basten GS, et al. Folate, DNA stability and colo-rectal neoplasia. Proc Nutr Soc 2004;63:571-8.

50. Christensen KE, MacKenzie RE. Mitochondrial one-carbon metabolism is adapted to the specific needs of yeast, plants and mammals. BioEssays 2006;28:595-605.

51. Stover PJ, Field MS. Trafficking of intracellular folates. Adv Nutr 2011;2:325-31.

52. Momb J, Lewandowski JP, Bryant JD, Fitch R, Surman DRJ, et al. Deletion of Mthfd1l causes embryonic lethality and neural tube and craniofacial defects in mice. Proc Natl Acad Sci U S A 2013;110:549-54.

53. Koseki J, Konno M, Asai A, Colvin H, Kawamoto KJ, et al. Enzymes of the one-carbon folate metabolism as anticancer targets 
predicted by survival rate analysis. Sci Rep 2018;8:303.

54. Asai A, Koseki J, Konno M, Nishimura T, Gotoh N, et al. Drug discovery of anticancer drugs targeting methylenetetrahydrofolate dehydrogenase 2. Heliyon 2018;4:1-17.

55. Flier JS, Mueckler MM, Usher P, Lodish HFJ. Elevated levels of glucose transport and transporter messenger RNA are induced by ras or src oncogenes. Science 1987;235:1492-5.

56. M. J. Birnbaum, H. C. Haspel, O. M. Rosen, Transformation of Rat Fibroblasts by FSV Rapidly Increases Glucose Transporter Gene Transcription. Science 1987;235:1495-8.

57. Cantley LC. The phosphoinositide 3-kinase pathway. Science 2002;296:1655-7.

58. Bruce WR, Gaag HVD. A Quantitative Assay for the Number of Murine Lymphoma Cells capable of Proliferation in vivo. Nature 1963;199:79-80.

59. Larochelle A, Vormoor J, Hanenberg H, Wang JCY, Bhatia M, et al. Identification of primitive human hematopoietic cells capable of repopulating NOD/SCID mouse bone marrow: Implications for gene therapy. Nat Med 1996;2:1329-37.

60. Bonnet D, Dick JE. Human acute myeloid leukemia is organized as a hierarchy that originates from a primitive hematopoietic cell. Nat Med 1997;3:730-7.

61. Al-Hajj M, Wicha MS, Benito-Hernandez A, Morrison SJ, Clarke MF. Prospective identification of tumorigenic breast cancer cells. Proc Natl Acad Sci U S A 2003;100:3983-8.

62. Chen R, Nishimura MC, Bumbaca SM, Kharbanda S, Forrest WF, et al. A Hierarchy of Self-Renewing Tumor-Initiating Cell Types in Glioblastoma, Cancer Cell 2010;17:362-75.

63. Prince ME, Sivanandan R, Kaczorowski A, Wolf GT, Kaplan MJ, et al. Identification of a subpopulation of cells with cancer stem cell properties in head and neck squamous cell carcinoma. Proc. Natl. Acad Sci U S A 2007;104:973-8.

64. O’Brien CA, Pollett A, Gallinger S, Dick JE. A human colon cancer cell capable of initiating tumor growth in immunodeficient mice. Nature 2007;445:106-10.

65. Ricci-Vitiani L, Lombardi DG, Pilozzi E, Biffoni M, Todaro M, et al. Identification and expansion of human colon-cancer-initiating cells. Nature 2007;445:111-5.

66. Klonisch T, Wiechec E, Hombach-Klonisch S, Ande SR, Wesselborg S, et al. Cancer stem cell markers in common cancers therapeutic implications. Trend Mol Med 2008;14:450-60.

67. Kim WT, Ryu CJ. Cancer stem cell surface markers on normal stem cells. BMB Rep 2017;50:285-98.

68. Vlashi E, Kim K, Lagadec C, Donna LD, McDonald JT, et al. In Vivo Imaging, Tracking, and Targeting of Cancer Stem Cells. J Natl Cancer Inst 2009;101:350-9.

69. Tamari K, Hayashi K, Ishii H. Identification of chemoradiation-resistant osteosarcoma stem cells using an imaging system for proteasome activity. Int J Oncol 2014;45:2349-54.

70. Hayashi K, Tamari K, Ishii H. Visualization and characterization of cancer stem-like cells in cervical cancer. Int J Oncol 2014;45:2468-74.

71. Yang J, Weinberg RA. Epithelial-mesenchymal transition: at the crossroads of development and tumor metastasis. Dev Cell 2008;14:818-29.

72. Polyak K, Weinberg RA. Transitions between epithelial and mesenchymal states: acquisition of malignant and stem cell traits. Nat Rev Cancer 2009;9:265-73.

73. Gupta PB, Onder TT, Jiang G, Tao K, Kuperwasser C, et al. Identification of selective inhibitors of cancer stem cells by highthroughput screening. Cell 2009;138:645-59.

74. Ohta K, Haraguchi N, Kano Y, Kagawa Y, Konno M, et al. Depletion of JARID1B induces cellular senescence in human colorectal cancer. Int J Oncol 2013;42:1212-8.

75. Kano Y, Konno M, Ohta K, Haraguchi N, Nishikawa S, et al. Jumonji/Arid1b (Jarid1b) protein modulates human esophageal cancer cell growth. Mol Clin Oncol 2013;1:753-7.

76. McAllister TE, England KS, Hopkinson RJ, Brennan PE, Kawamura A, et al. Recent Progress in Histone Demethylase Inhibitors. J Med Chem 2016;59:1308-29.

77. Shay JW, Wright WE. Hayflick, his limit, and cellular ageing. Nat Rev Mol Cell Biol 2000;1:72-6.

78. Blasco MA. Telomeres And Human Disease: Ageing, Cancer And Beyond. Nat Rev Genet 2005;6:611-2.

79. Cesare AJ, Reddel RR. Alternative lengthening of telomeres: models, mechanisms and implications. Nat Rev Genet 2010;11:391-30.

80. Jafri MA, Ansari SA, Alqahtani MH, Shay JW. Roles of Telomeres and Telomerase in Cancer, and Advances in Telomerase-targeted Therapies. Genome Med 2016;8:69.

81. Yakhini Z, Jurisica I. Cancer computational biology. BMC Bioinform 2011;12:120.

82. Beerenwinkel N, Greenman CD, Lagergren J. Computational Cancer Biology: An Evolutionary Perspective. PLoS Comput Biol 2016;12:e1004717.

83. Yagi K, Kubota H, Hatano A, Kuroda S. Trans-Omics: How To Reconstuct Biochemical Networks Across Multiple 'Omic' Layers. Trend Biotechnol 2016;34:276-90.

84. Hasin Y, Seldin M, Lusis A. Multi-omics approaches to disease. Genome Biol 2017;18:83.

85. Koseki J, Matsui H, Konno M, Nishida N, Kawamoto K, et al. A Trans-omics Mathematical Analysis Reveals Novel Functions of the Ornithine Metabolic Pathway in Cancer Stem Cells. Sci Rep 2016;6:20726.

86. Konno M, Matsui H, Koseki J, Asai A, Kano Y, et al. Computational trans-omics approach characterized methylomic and transcriptomic involvements and identified novel therapeutic targets for chemoresistance in gastrointestinal cancer stem cells. Sci Rep 2018;8:899.

87. Tamari K, Konno M, Asai A, Koseki J, Hayashi K, et al. Polyamine flux suppresses histone lysine demethylases and enhances ID1 expression in cancer stem cells. Cell Death Discov 2018;4:104. 